\title{
Valuing Employee Stock Options: Implications for the Implementation of NZ IFRS 2*
}

\author{
Glenn Boyle ${ }^{\dagger}$ \\ NZ Institute for the Study of Competition and Regulation \\ Victoria University of Wellington
}

Stefan Clyne

Global Banking

Deutsche Bank AG

Helen Roberts

Department of Finance and Quantitative Analysis

University of Otago

* For help with various aspects of this paper, we are grateful to Scott Chaput, Timothy Crack, Jonathan Ingersoll, Martin Lally, Tony van Zijl, an anonymous referee, and seminar participants at Otago and the 2006 NZ Finance Colloquium. However, any remaining errors or ambiguities are solely the responsibility of the authors. The views expressed in this paper are not necessarily those of Deutsche Bank AG.

$\dagger$ Corresponding author: glenn.boyle@vuw.ac.nz 


\begin{abstract}
From 2007, New Zealand firms must report the cost of granting employee stock options (ESOs). Market-based option pricing models assume that option holders are unconstrained in their portfolio choices and thus are indifferent to the specific risk of any firm. By contrast, ESO holders are frequently required to hold portfolios that are over-exposed to the firm that employs them and so adopt exercise policies that reflect their individual risk preferences. Applying the model of Ingersoll (2006) to hypothetical ESOs, we show that ESO cost can be extremely sensitive to employee characteristics of risk aversion and under-diversification. This result casts doubt on the usefulness of any market-based model for pricing ESOs, since such models, by definition, produce option values that are independent of employee characteristics. By limiting employee discretion over the choice of exercise date, vesting restrictions help reduce the magnitude of this problem.
\end{abstract}




\section{(1) INTRODUCTION}

In recent years, employee stock options (ESOs) have been the subject of much criticism. To many, the seemingly attractive link between pay and performance that ESOs offer has been soured by their association with exorbitant compensation packages, repricing in favour of ESO recipients, and general corporate malfeasance. In essence, they have come to be seen as a symptom of the owner-manager agency problem rather than as a solution to it.

One commonly cited reason for the failure of ESOs to live up to their potential is the absence of an accounting standard requiring firms to treat ESOs as a compensation expense. As far as reported profits are concerned, ESOs have been a free lunch, thereby encouraging the granting of too many of them on too generous terms. In response to these concerns, accounting authorities have recently taken steps to ensure that the costs of ESOs will in future be recognised in financial statements. The principal authority on this issue is International Financial Reporting Standard 2 (IFRS 2), issued in March 2004 by the International Accounting Standards Board (IASB 2004). In November 2004, the Institute of Chartered Accountants of New Zealand adopted the same requirements in NZ IFRS 2. In brief, this specifies that all NZ firms must begin recognising ESOs at their grant date 'fair value' (essentially the value the ESOs would trade at in the marketplace) by no later than 2007 , and provides principles-based guidance on how fair value should be determined.

On the latter issue, the value of market-traded options has traditionally been calculated using the famous model of Black and Scholes (1973) and Merton (1973) or some variant thereof, but IFRS 2 notes that ESOs differ in at least two ways from the type of option envisaged by those authors (henceforth BSM) and that an appropriate calculation of ESO cost should reflect these differences. First, the BSM model values a European call option for which exercise prior to the expiration date is impossible, whereas ESOs typically allow early exercise. If early exercise were valuable (as would be the case if the underlying asset paid dividends), then the BSM model underestimates the true option value. Thus, even in the absence of any other differences, the BSM 
model would not necessarily provide an accurate estimate of ESO cost. Of course, as IFRS 2 recognises, this problem can easily be overcome by the use of market-based option pricing models that explicitly allow for early exercise.

Second, and more importantly, ESO holders are typically subject to trading restrictions that result in over-exposure to the firm that employs them. ${ }^{1}$ Because they are thus under-diversified, they choose to exercise their ESOs earlier than would otherwise be the case. Although the chosen exercise date is optimal from the perspective of the individual holder, it is sub-optimal from the perspective of the market, so the cost to the firm of issuing ESOs differs from the value suggested by a market-based model. However, IFRS 2 is largely silent on this matter, beyond suggesting that it be accommodated either by using the expected exercise date in BSM or by employing some other market-based model that incorporates early exercise, so the extent to which it is material for valuation purposes is unclear.

In this paper, we attempt to shed some light on this issue and assess its implications for accounting recognition of ESO costs. Using a pricing model that explicitly incorporates trading restrictions, we calculate the 'true' cost of two hypothetical ESOs and compare these with the values generated by the sorts of methods discussed in IFRS 2. Our principal finding is that, in contrast to the value estimates obtained from market-based models, the cost of issuing ESOs is quite sensitive to the risk aversion and under-diversification characteristics of the employee. Consequently, any estimate from a market-based model approaches the true cost of any particular ESO only by good luck.

In recent years, a number of studies have developed methods for valuing ESOs. Our analysis is based on the model of Ingersoll (2006); others include Carpenter (1998), Hall and Murphy (2002), Huddart (1994), Kulatilaka and Marcus (1994), and Maller et al (2002). However, with the indirect exception of Carpenter, none of these

1 Under-diversification can arise in a wide variety of situations; see, for example, Emanuel and Maher (2005) on the case of Fonterra dairy farmers. 
explicitly calculate the sensitivity of ESO cost to employee characteristics and the implications of this for accurate financial reporting. ${ }^{2}$

In the next section, we discuss in more detail some of the issues that arise in valuing ESOs and outline the method we use for calculating the true cost of ESOs. Section 3 describes the model of Ingersoll (2006) for valuing ESOs and contains our results, while section 4 offers some concluding remarks.

\section{(2) WHAT DETERMINES THE COST OF ESOS?}

In the absence of trading constraints, investors diversify their asset portfolios and thus are essentially risk-neutral with respect to firm-specific risk. Hence, the value of an option equals its expected payoff discounted at a rate that includes a premium for systematic (non-diversifiable) risk only. ${ }^{3}$ However, ESO holders typically have a large over-investment in the firm that grants the ESOs: in addition to not being able to sell their ESOs, many have (and in some cases are required to have) substantial stock holdings and, just as importantly, all have a large amount of human capital tied up in the firm, at least some of which is unique to that firm. Consequently, ESO recipients are under-diversified and thus exposed to the unsystematic risk of the issuing firm. As a result, the value (to the recipient) of an ESO equals its expected payoff discounted at a rate that includes a premium for both systematic and firm-specific risk. In short, trading restrictions lower the subjective value placed on ESOs by their holders.

However, this phenomenon is not directly relevant to the value that investors and accountants are interested in - the cost incurred by the firm in granting ESOs. To understand the difference, suppose an employee's remuneration contract includes the use of a $\$ 50,000$ car. If the employee does not drive, or lives only a short distance

2 In related work, Henderson (2005) considers the case of a manager holding a real option on an asset that cannot be traded and whose risk is only partially hedgable. Similar to this paper, she finds that these constraints lead to earlier exercise and lower option value.

3 Models of option pricing are typically cast in a certainty-equivalent cashflow, rather than risk-adjusted discount rate, framework (although see Arnold and Crack, 2004), but the latter's intuition is better suited to our purpose here. 
from the workplace, then the value he places on the car is likely to be considerably less than $\$ 50,000$, and may approach zero. But the cost to the firm is still $\$ 50,000$. And exactly the same principle applies to ESOs. The opportunity cost to the firm is the value of the ESO in the marketplace (i.e., the expected ESO payoff discounted at a rate including a premium for systematic risk only) since the funds potentially used to pay out the option could otherwise have been invested elsewhere in the market; the particular circumstances of the ESO holder are irrelevant.

Nevertheless, the preferences and diversification of the ESO holder do have an indirect effect on the cost of ESOs to the firm. Returning to the company car analogy, the total cost to the firm depends on the employee's usage policy, insofar as a car that has been only lightly used will generally have a greater resale value than one with many kilometres on the clock. With ESOs, the cost to the firm depends on the employee's exercise policy. If that employee is under-diversified, then he seeks to reduce the resulting exposure to the firm's unsystematic risk by exercising the ESO earlier than would otherwise be the case. Early exercise changes the expected option payoff, and so the cost to the firm equals this revised expected payoff discounted at the systematic-risk-adjusted rate used by the market. Thus, the cost to firms of granting ESOs differs from the value of otherwise-equivalent options traded in the market not because the circumstances under which ESOs are issued make them less valuable to recipients, but rather because these same circumstances affect the optimal exercise policy of recipients, thereby changing the option payoff distribution.

Of course, it may be that employee characteristics have only a minor impact on ESO exercise policy and fair value, and thus can safely be ignored for reporting purposes, but this cannot simply be assumed. Instead, we need some mechanism for assessing the sensitivity of fair value to employee characteristics, which in turn requires that employee exercise policy be determined simultaneously with the option price. The model of Ingersoll (2006) is particularly suitable for this purpose: it determines the optimal exercise policy for an ESO and then calculates the marketplace cost of the ESO to the firm given this policy. 
Intuitively, this model proceeds in three steps. ${ }^{4}$ First, a risk-averse employee chooses the asset portfolio that maximises expected lifetime utility subject to a constraint that some minimum proportion of the portfolio be invested in the firm in which he is employed. Second, given this portfolio, the employee chooses the ESO exercise policy that maximises his personal present value of the expected option payoff. Because he is over-exposed to the firm issuing the ESO, the implicit discount rate used in this optimisation, and hence his chosen exercise policy, depends on both the extent of this over-exposure and on his risk preferences. Third, the cost to the firm is calculated by discounting, at the appropriate market rate, the expected ESO payoff generated by the employee's exercise policy. Somewhat loosely, we can think of the first two steps as determining the optimal employee-specific exercise date, with the third step then calculating the market value of exercising the option at this date.

A simple example may help illustrate this approach. ${ }^{5}$ Consider an ESO that (i) is written on a stock currently trading at $\$ 10$, (ii) is exercisable in either of the next two years, (iii) has an exercise price of $\$ 10.30$. In addition, as shown in Figure 1, the price $\mathrm{S}_{\mathrm{t}}$ of the stock (which does not pay dividends) either rises by $20 \%$ or falls by $15 \%$ with equal probability in each of the next two years.

\section{[Insert Figure 1 about here]}

The value of this ESO is determined by, and simultaneously with, the optimal exercise policy. The general nature of the latter is obvious: keep the ESO alive if its value is greater than the exercise payoff, otherwise exercise. At date 2, the value from

4 A more formal description appears in section 3.

5 The reader should be aware that this example is intended only to capture the intuition underlying the link between ESO holder characteristics, the effect these have on the holder's optimal exercise policy, and the implications of this policy for ESO value. It does not describe the specific details of the general valuation model we use in the next section. In particular, that model is based on risk-neutral pricing and thus has no explicit need for actual probabilities and risk-adjusted discount rates. However, we use the latter concepts in this example as they allow for simpler exposition and thus are better geared towards intuitive understanding. 
retaining the ESO is zero (since it expires at that date), so a necessary and sufficient condition for exercise is simply that the exercise payoff be positive. As a result, exercise occurs at date 2 if and only if $S_{2}=\$ 14.40$, since this is the only state in which the stock price exceeds the exercise price. At date 1, however, retaining the ESO is a viable alternative to exercising it, so the latter is justified if and only if the payoff exceeds the value of retaining the option until date 2. Clearly, this is a possible strategy if and only if $S_{1}=\$ 12$; whether or not it is optimal depends on the date 1 value of the ESO. In turn, the current (date 0) ESO value depends on whether or not exercise will occur at date 1.

To obtain the date 0 ESO value, we proceed in three discrete steps. First, we calculate the date 1 ESO value, given the exercise policy that will prevail at date 2 . Second, we use this value to determine the optimal exercise policy at date 1 . Third, we use the date 1 payoffs implied by this policy to calculate the date 0 ESO value. The date 1 value is obviously crucial to this process since it determines the date 1 exercise policy and hence the current value. Because the ESO must be held in an underdiversified portfolio, a risk-averse employee requires additional compensation for bearing firm-specific risk. Accordingly, the date 1 value of the ESO to the employee will be less than its market value, and thus the employee is more likely to exercise at date 1 than purely market considerations would suggest.

To make this point concrete and demonstrate its implications, we assume that the implicit discount rate embedded in the market value of the ESO is $10 \%$, while that used by a hypothetical, risk-averse, and under-diversified employee is $25 \%{ }^{6}$ Then the market value of the ESO at date 1 is

$$
\mathrm{V}_{\mathrm{m} 1}=\frac{\text { \{probability of } \left.\mathrm{S}_{2}=14.40\right\} \times\left\{\text { exercise payoff if } \mathrm{S}_{2}=14.40\right\}}{1.1}
$$

6 Note that Figure 1 implies that the discount rate on the stock itself is $2.5 \%$, so the ESO is significantly riskier than the stock. This is a standard feature of call options such as ESOs - see Boyle and Irwin (2004). In the next section, we allow all these discount rates to be determined endogenously as part of the equilibrium process, rather than arbitrarily set as in this example. 


$$
\begin{aligned}
& =\frac{\{0.5\} \times\{14.40-10.30\}}{1.1} \\
& =1.86
\end{aligned}
$$

Since $\$ 1.86>\$ 1.70$ (the payoff from exercising the ESO at date 1), the ESO is worth more alive than dead at date 1 and so the optimal policy from the market's perspective is to not exercise at date 1 . As a result, the date 0 market value of the ESO is simply the present value of an asset that is worth $\$ 1.86$ in one year's time with probability 0.5 and zero otherwise. That is

$$
\begin{aligned}
\mathrm{V}_{\mathrm{m} 0} & =\frac{\left\{\text { probability of } \mathrm{S}_{1}=12\right\} \times\left\{\text { ESO value if } \mathrm{S}_{1}=12\right\}}{1.1} \\
& =\frac{\{0.5\} \times\{1.86\}}{1.1} \\
& =0.85
\end{aligned}
$$

The calculation from the under-diversified employee's perspective is similar, but all payoffs are discounted at $25 \%$ rather than $10 \%$. His subjective date 1 valuation of the ESO is

$$
\begin{aligned}
\mathrm{V}_{\mathrm{e} 1} & =\frac{\text { \{probability of } \left.\mathrm{S}_{2}=14.40\right\} \times\left\{\text { exercise payoff if } \mathrm{S}_{2}=14.40\right\}}{1.25} \\
& =\frac{\{0.5\} \times\{14.40-10.30\}}{1.25} \\
& =1.64
\end{aligned}
$$

which is less than the date 1 exercise payoff (1.70), so the optimal policy from the employee's perspective is to exercise at date 1 . Therefore, the employee's date 0 value of the ESO is equal to his subjective present value of an asset that is worth $\$ 1.70$ in one year's time with probability 0.5 and zero otherwise. That is

$$
\mathrm{V}_{\mathrm{e} 0}=\frac{\text { \{probability of } \left.\mathrm{S}_{1}=12\right\} \times\left\{\text { ESO value if } \mathrm{S}_{1}=12\right\}}{1.25}
$$




$$
\begin{aligned}
& =\frac{\{0.5\} \times\{1.70\}}{1.25} \\
& =0.68
\end{aligned}
$$

which is $20 \%$ less than the market value of 0.85 . However, neither $\mathrm{V}_{\mathrm{m} 0}$ nor $\mathrm{V}_{\mathrm{e} 0}$ represents the cost of the ESO to the firm; the former assumes an exercise policy, and hence an expected payout, different from that actually followed by the employee, while the latter assumes an opportunity cost of funds different from that faced by the firm. Instead, the cost to the firm is the present market value of the expected liability created by the employee's exercise policy. That is

$$
\begin{aligned}
\mathrm{C}_{0} & =\frac{\left\{\text { probability of } \mathrm{S}_{1}=12\right\} \times\left\{\text { ESO market value if } \mathrm{S}_{1}=12\right\}}{1.1} \\
& =\frac{\{0.5\} \times\{1.70\}}{1.1} \\
& =0.77
\end{aligned}
$$

which is less than the market value $(0.85)$, but greater than the employee value $(0.68)$. Under-diversification and risk aversion lower the value of the ESO to the employee, but are irrelevant for market discount rates and hence for the option's market value. But by inducing early exercise of the ESO, they also lower the cost of the ESO to the firm, to a level between between the market value and the employee value. Figure 2 summarises this outcome.

\section{[Insert Figure 2 about here]}

Our focus in this paper is on the calculation of $\mathrm{C}_{0}$. In contrast to the simple example above, the procedure we follow endogenously determines the implicit market and employee discount rates as functions of market conditions and employee characteristics respectively, so the values we obtain are consistent with market equilibrium (which may not be the case in the example). Of course, because employee 
characteristics of risk aversion and under-diversification are essentially unobservable, this procedure will be difficult to apply in practice. However, by calculating the actual costs of hypothetical ESOs, it can tell us something about the likely accuracy of practical methods that ignore employee-specific parameters. This is the goal of the remainder of this paper.

\section{(3) CALCULATING THE COST OF ESOS}

In Ingersoll (2006), the employee has an expected lifetime utility function of the form:

$$
E_{0}\left[\frac{1}{1-\gamma} \int_{0}^{\infty} e^{-\rho t} C_{t}^{1-\gamma} d t\right]
$$

where $C_{t}$ is date $t$ consumption, $\gamma$ is the coefficient of relative risk aversion, and $\rho$ represents employee "impatience". The employee chooses an investment plan that maximises (1) subject to a constraint that he holds an excess fraction $\alpha$ of his wealth in the stock of his own firm, over and above the optimal unconstrained holding. For example, $\alpha=0.5$ means that the employee holds $50 \%$ more of his wealth in the firm that employs him than he would if he were unconstrained; given the importance of human capital in the wealth of most employees, such a figure may not be especially high. In general, we can think of $\alpha$ as capturing the employee's level of underdiversification.

As noted earlier, ESOs can typically be exercised prior to expiration and are thus so-called American options. Because there is no known analytical formula for the value of such an option, a numerical approximation technique must instead be used. Ingersoll (2006) adopts the "barrier-derivative" method in which the ESO is exercised as soon as the company's stock price reaches some critical value $\mathrm{K}^{*}$, where $\mathrm{K}^{*}$ is chosen so as to maximise the employee's subjective present value of the ESO payoff. The cost of the ESO to the firm is then just the market value of the expected payoff associated with the employee's chosen exercise policy. More formally, let $\pi(K)$ denote 
the employee's subjective present value of the ESO payoff under the threshold price K, with $\Pi(K)$ being the corresponding market value. Then the exercise policy satisfies

$\begin{array}{ll}\text { Exercise } & \text { if stock price } \geq \mathrm{K}^{*} \\ \text { Do not Exercise } & \text { if stock price }<\mathrm{K}^{*}\end{array}$

where $\mathrm{K}^{*}$ is the value of $\mathrm{K}$ that solves

$$
\underset{\mathrm{K}}{\operatorname{Max}} \pi(\mathrm{K})
$$

and the cost of ESO issuance is then given by

$$
\mathrm{C}_{0}=\Pi\left(\mathrm{K}^{*}\right)
$$

Note that $\mathrm{K}^{*}$, and hence $\mathrm{C}_{0}$, will depend on $\alpha$ and $\gamma$. The greater is underdiversification or risk aversion, the less willing the employee is to be exposed to the additional firm-specific risk associated with the ESO, and hence the lower the value of $\mathrm{K}^{*} \cdot{ }^{7}$

To illustrate the impact of trading restrictions and early exercise on ESO value, we apply this model to two hypothetical ESOs, the details of which appear in Table 1. ESO I is an in-the-money option granted by a firm with moderate volatility and dividend yield; ESO II is an out-of-the-money option granted by a firm with high volatility that pays no dividends. If these were standard market-traded options, exercise prior to expiration would potentially be optimal for ESO I (because of its positive dividend yield), but not for ESO II. ${ }^{8}$

7 In the numerical example of section 2, this effect is captured by the higher discount discount rate used by the employee.

8 See Hull (2003, pp175-177) for a demonstration of the point that a call option on a non-dividend-paying stock should never be exercised prior to the expiration date. 
ESOs are often issued with so-called vesting restrictions, i.e., they cannot be exercised prior to the vesting date. We initially assume that both ESOs have vested; subsequently we consider the case where they vest at the dates listed in Table 1.

\section{[Insert Table 1 about here]}

\subsection{Trading restrictions and early exercise for ESOs that have vested}

We programme the model summarised by equations (2) and (3) using VBA in Excel, allow $\alpha$ to take any value between 0.00 and 1.00, and report results for $\gamma=1,5$, 10. ${ }^{9}$ For comparison purposes, we also report the corresponding BSM value. ${ }^{10}$

Figure 3 plots these calculations for ESO I. For low employee risk aversion $(\gamma$ $=1$ ), the true cost to the firm is very close to the BSM value of $\$ 0.26$. Indeed, unless the employee has virtually all of his wealth tied up in the firm, the actual ESO cost is greater than the BSM value. This reflects the optimality of early exercise in the presence of a positive dividend yield. For more risk-averse employees, however, the desired exercise date is sufficiently early to be sub-optimal from the market's perspective and the actual cost falls below the BSM value. The deviation can be significant: a risk-intolerant employee $(\gamma=10)$ with an additional $50 \%$ of his wealth tied up in his firm creates an ESO cost that is little more than half the BSM value. Intuitively, such an employee chooses to eliminate the diversification risk associated with the ESO by exercising it particularly early. Although this maximises the expected payoff discounted at the employee's (high) subjective discount rate, it results in a lower (relative to holding until expiration) discounted expected payoff from the market's perspective.

9 Cochrane (2001) notes that a reasonable value of $\gamma$ is usually taken to be between three and five. Some idea of what these values mean in the New Zealand context can be inferred from the return means and volatilities reported in Lally and Marsden (2004): these imply that a NZ investor with $\gamma$ equal to one should invest approximately $130 \%$ of his wealth in the stockmarket; the corresponding values for $\gamma$ equal to five and ten are $30 \%$ and $15 \%$ respectively.

10 The BSM model is sufficiently well known to not require explicit description here; discussions are standard fare in all introductory finance textbooks. For a detailed explanation, see Crack (2004). 


\section{[Insert Figure 3 about here]}

The situation with ESO II is somewhat different. Its much higher stock price volatility means that even risk-tolerant employees desire exercise that is sub-optimally early from the market's perspective (especially as the stock pays no dividends), and so the cost to the firm is always, and often substantially, less than the BSM value. Even a moderately risk-averse $(\gamma=5)$ and moderately over-exposed $(\alpha=0.3)$ employee costs the firm only $40 \%$ of the BSM value of $\$ 0.59$. For such an ESO, the BSM model provides inaccurate estimates of the cost to the firm.

\section{[Insert Figure 4 about here]}

The differences between the various curves in Figures 3 and 4 reflect differences in exercise policy. For example, an unconstrained employee $(\alpha=0)$ has an expected time to exercise for ESO I of 4.4 years (resulting in a current value of \$0.28), but an employee with $\alpha=0.25$ and $\gamma=5$ expects to exercise before three years are up (lowering the ESO cost to $\$ 0.25$ ); increasing $\alpha$ to 0.75 means that exercise is expected to occur in approximately fifteen months (with a resultant ESO cost of \$0.17). Although the positive dividend yield on the ESO I stock means that some degree of early exercise is likely to be optimal from the market's perspective, the combined effects of risk aversion and under-diversification lead holders to exercise earlier still, thereby lowering the market value of the ESO.

Figures 3 and 4 confirm the commonly held view that the BSM value may differ significantly from the actual cost incurred by firms in issuing ESOs. This raises the question of whether the BSM model can be adjusted in some simple way to approximate the effects of under-diversification and early exercise. In this regard, the usual recommendation - contained in IFRS 2 (para B17) - is to use the expected exercise date in place of the expiration date in the BSM model. 
Evaluation of this suggestion requires some method of estimating the expected exercise date. The standard, and probably the only practical, way of doing so is to extract some measure, typically the average, from data on previous exercise decisions. Thus, for example, if past experience revealed that the average exercise date was one month after vesting, then the expected time to exercise in the BSM adjusted model would be 19 months for ESO I and seven months for ESO II. However, such a procedure ignores employee-specific variation in the expected time to exercise and hence in ESO cost.

To illustrate this point explicitly, we re-calculate the BSM value using an expected exercise date equal to one month after vesting, and compare this with the true cost already obtained from equations (2) and (3). As can be seen in Figure 5, the adjustment arguably makes matters worse. Whereas previously (Figures 3 and 4 ) the BSM value was close to the actual cost for employees with low risk aversion and generally an upper bound for less risk tolerant holders, now it is a significant underestimate for employees with low risk aversion and subject to pricing errors of both sign for others. In other words, the adjustment has increased the absolute magnitude of error in some cases, while in others it has introduced ambiguity, where none previously existed, about the sign of error.

\section{[Insert Figure 5 about here]}

Note that this outcome is not an artifact of the particular expected exercise date we have assumed. Any exercise date used in any model that generates an option value which is independent of employee characteristics will have similar problems. Given that actual ESO costs are so sensitive to employee characteristics, it is obvious that any method or model that ignores these characteristics will produce cost estimates that are subject to substantial error. Put another way, the problem with using BSM for ESO valuation is not so much that employees may wish to exercise earlier than BSM allows, but rather that they will do so to differing degrees. That is, in terms of Figures 3 and 4, 
any value estimate based on a homogeneous expected exercise date is a horizontal line, and so will approach the true cost of any particular ESO only by good fortune.

Option pricing models that are more flexible than BSM, such as the Binomial model, cannot overcome this problem. If the exercise policy embedded in the Binomial model is not related to employee characteristics, then the resulting value is no more useful than the BSM value precisely because it ignores inter-employee variation. And if employee characteristics are incorporated in the Binomial model calculation, then the problem of observing these characteristics in order to apply the model in practice arises. ${ }^{11}$ In the absence of reliable information about employee characteristics, firms have the opportunity to manipulate ESO valuations in selfinterested ways, thereby negating the intention that these valuations should provide more information to investors.

To summarise, the important feature of Figures 3 and 4 is not that the true cost of ESOs can differ from the BSM value. Of much greater consequence is the sensitivity of ESO cost to employee characteristics of under-diversification and risk aversion. Precisely because these parameters have no role in any market-based option pricing model, no such model, not just BSM, can be expected to accurately estimate ESO cost.

\subsection{Trading restrictions and early exercise for ESOs that have not vested}

Vesting restrictions have two effects on ESO cost. First, they increase the probability that some options will never become eligible for exercise because, for example, workers cease employment with the firm before the vesting period ends. Second, they reduce the period of time in which exercise can occur. IFRS 2 requires that the first effect be recognised by adjusting the quantity, rather than the price, of ESOs. Here we focus on the second effect as this relates most closely to the exercise policy issue analysed above.

11 In this situation, the Binomial model is essentially the Ingersoll (2006) model with longer time steps. 
To do so, we recalculate the actual costs of our hypothetical ESOs incorporating the vesting restrictions listed in Table 1, i.e., that ESO I cannot be exercised for 18 months and ESO II for six months. In Figure 6, we illustrate the effects of this restriction for the latter option. ${ }^{12}$ The solid curve depicts the cost of a vested ESO II held by an employee with $\gamma=5$; the dashed curve shows the same cost when vesting occurs in six months time. The latter lies on or above the former, so imposing vesting restrictions raises the cost of ESO II.

\section{[Insert Figure 6 about here]}

This result seems surprising, insofar as restricting the dates on which ESOs can be exercised unambiguously reduces their value to employees, but the reason is straightforward: employees who would otherwise have exercised their options suboptimally early from the market's perspective (i.e., prior to the vesting date) are now forced to wait until a later date that offers an expected payoff with a higher market value. Note, however, that this need not always be the case: if market value maximisation required exercise before the vesting date (as might be the case for a firm with a high dividend yield, for example), then vesting would enforce sub-optimal late exercise and thus lower the ESO cost.

Regardless of whether it raises or lowers ESO cost, vesting always reduces the sensitivity of ESO cost to employee characteristics. As Figure 6 indicates, the slope of the curve depicting the relationship between ESO cost and holder under-diversification is less steep with the six-month vesting period. Similarly, the vertical gap between curves of different risk aversion (not drawn) is also smaller with vesting. In effect, vesting places restrictions on employees' abilities to exercise early and thus on their freedom to choose an exercise policy that optimally reflects their individual circumstances.

12 The vertical difference between the two curves is even more pronounced for the longer vesting period of plan I. 
The importance of this point is that vesting helps reduce the inaccuracy of market-based option pricing models that ignore employee characteristics. As the vesting period increases, the importance of these characteristics for ESO cost becomes smaller and market-based models are more likely to provide accurate estimates of ESO cost.

\section{(4) CONCLUDING REMARKS}

Using models of market-traded options to determine the cost of ESOs is a task fraught with difficulty. Because ESO holders are often under-diversified, they choose to exercise ESOs earlier than would otherwise be the case. Although such early exercise is optimal from the employee's perspective, it is frequently premature from the perspective of the market, and hence ESOs are generally less costly than otherwiseequivalent marketplace options.

Because the cost of ESOs is sensitive to characteristics of the employee to whom they are granted, standard market-based models that ignore these characteristics are likely to produce value estimates that differ substantially from the true cost. Commonly-cited adjustments, such as using the expected exercise date in place of the expiration date in the BSM model, or determining the optimal exercise date endogenously within the Binomial model, leave this fundamental problem unresolved. The difficulty with applying market-based models to ESOs is not early exercise per se, but rather the factors underlying such early exercise.

The fundamental dilemma confronting ESO valuation is simply this. On the one hand, standard market-based models of option pricing ignore features integral to the cost of ESOs. On the other hand, quantification of these features is necessarily subjective, thereby creating the potential for manipulation.

Fortunately, to end on an optimistic note, there may be practical methods that help mitigate this problem. First, it should be possible to 'back out' information about employee characteristics from data on actual exercise decisions. If such analysis revealed that these characteristics were clustered in a fairly tight range, then the issues 
highlighted in this paper are of less importance. Second, as shown in section 3.2, lengthy vesting periods reduce the sensitivity of ESO cost to holder characteristics. Third, the pricing model used in this paper assumes that ESO holders adopt an exercise policy that is optimal given their own particular circumstances. However, Carpenter (1998) shows that incorporating an exogenous stopping process in the standard marketbased model for pricing American options explains actual exercise decisions about as well as a more general employee-specific model. This suggests that a simple extension to market-based models may provide accurate ESO valuations without the need to incorporate subjective estimates of employee characteristics. Future research should investigate these issues in more detail. 


\section{References}

Arnold, T. and T. Crack (2004). Using the WACC to value real options. Financial Analysts Journal, 60, 78-82.

Boyle, G. and T. Irwin (2004). A primer on real options. INFINZ Journal, 1, 44-59.

Black, F. and M. Scholes (1973). The pricing of options and corporate liabilities, Journal of Political Economy, 81, 637-659.

Carpenter, J. (1998). The exercise and valuation of executive stock options. Journal of Financial Economics, 48, 127-158.

Cochrane, J. (2001). Asset Pricing, Princeton University Press, Princeton, USA.

Crack, T. (2004). Basic Black-Scholes: Option Pricing and Trading, www.BasicBlackScholes.com

Emanuel, D. and M. Maher (2005). The cost of cooperative ownership: estimates of the costs to Fonterra's farmer owners. Pacific Accounting Review, 17, 37-48.

Hall, B. and K. Murphy (2002). Stock options for undiversified employees. Journal of Accounting and Economics, 33, 3-42.

Henderson, V. (2005). Valuing the option to invest in an incomplete market. Princeton University Working Paper.

Huddart, S. (1994). Employee stock options, Journal of Accounting and Economics, $18,207-231$.

Hull, J. (2003). Options, Futures and Other Derivatives (5th ed.). Prentice Hall, New Jersey, USA.

Ingersoll, J. (2006). The subjective and objective evaluation of incentive stock options. Journal of Business, 79, 453-488.

International Accounting Standards Board (2004). IFRS 2: Share-based Payment, IASCF, London, England.

Kulatilaka, N. and A. Marcus (1994). Valuing employee stock options. Financial Analysts Journal, 50, 46-56.

Lally, M. and A. Marsden (2004). Tax-adjusted market risk premiums in New Zealand: 1931-2002. Pacific-Basin Finance Journal, 12, 291-310. 
Maller, R., R. Tan and M. Van De Vyver (2002). How might companies value ESOs? Australian Accounting Review, 12, 11-24.

Merton, R. (1973). The theory of rational option pricing. Bell Journal of Economics and Management Science, 4, 141-83. 


\section{Figure 1}

\section{Stock Price Evolution for Illustrative ESO}

Today (at date 0 ), the stock price is $\$ 10$. In subsequent years, it either rises by $20 \%$ or falls by $15 \%$, both with probability 0.5 .

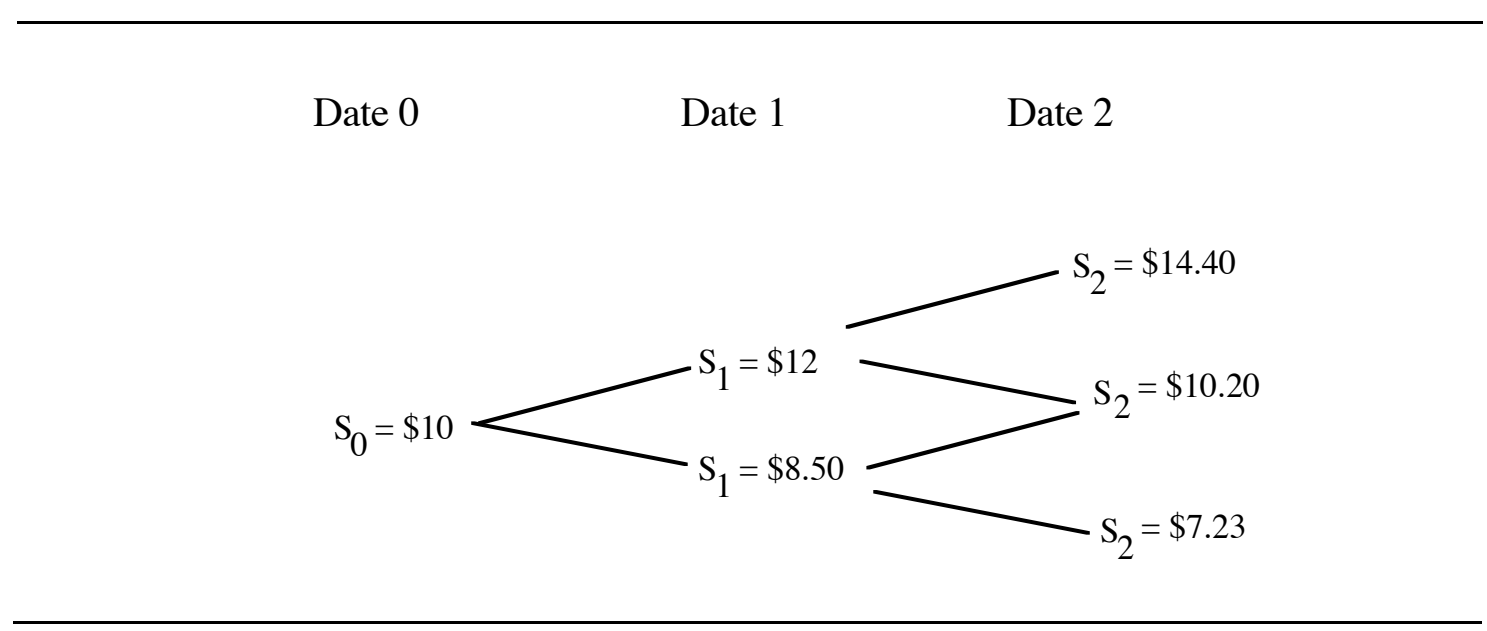




\section{Figure 2}

\section{Values for Illustrative ESO}

Today (at date 0 ), the stock price is $\$ 10$. In subsequent years, it either rises by $20 \%$ or falls by $15 \%$, both with probability 0.5 . The ESO can be exercised at either date 1 or date 2 in return for a payment of $\$ 10.30 . \mathrm{V}_{\mathrm{mt}}$ is the date $\mathrm{t}$ market value of the ESO; $\mathrm{V}_{\text {et }}$ is the corresponding subjective employee value; $\mathrm{C}_{0}$ is the date 0 cost to the firm.

Date 0 Date $1 \quad$ Date 2

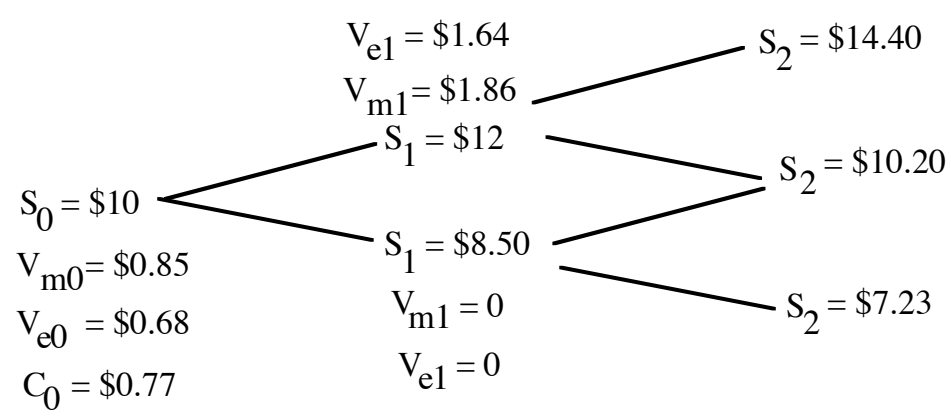


Table 1

\section{Hypothetical ESO Details}

Parameter values for two hypothetical ESOs. In addition, the riskless interest rate is $5 \%$, market volatility is $20 \%$, and the beta of both underlying stocks is 0.9 .

\begin{tabular}{lll} 
& ESO I & ESO II \\
\hline Current stock price & $\$ 1.00$ & $\$ 0.90$ \\
Exercise price & $\$ 0.90$ & $\$ 1.00$ \\
Stock price volatility & 0.30 & 0.80 \\
Dividend yield & 0.04 & 0.00 \\
Expiration date & 5 years & 5 years \\
Vesting date (section 3.1) & vested & vested \\
$\quad$ (section 3.2) & 18 months & 6 months \\
\hline
\end{tabular}


Figure 3

\section{Valuing ESO I}

This figure plots the Ingersoll (2006) cost of ESO I for various combinations of employee risk aversion $(\gamma)$ and under-diversification $(\alpha)$, and compares these with the Black-Scholes-Merton (BSM) value. Parameter values for ESO I are in Table 1.

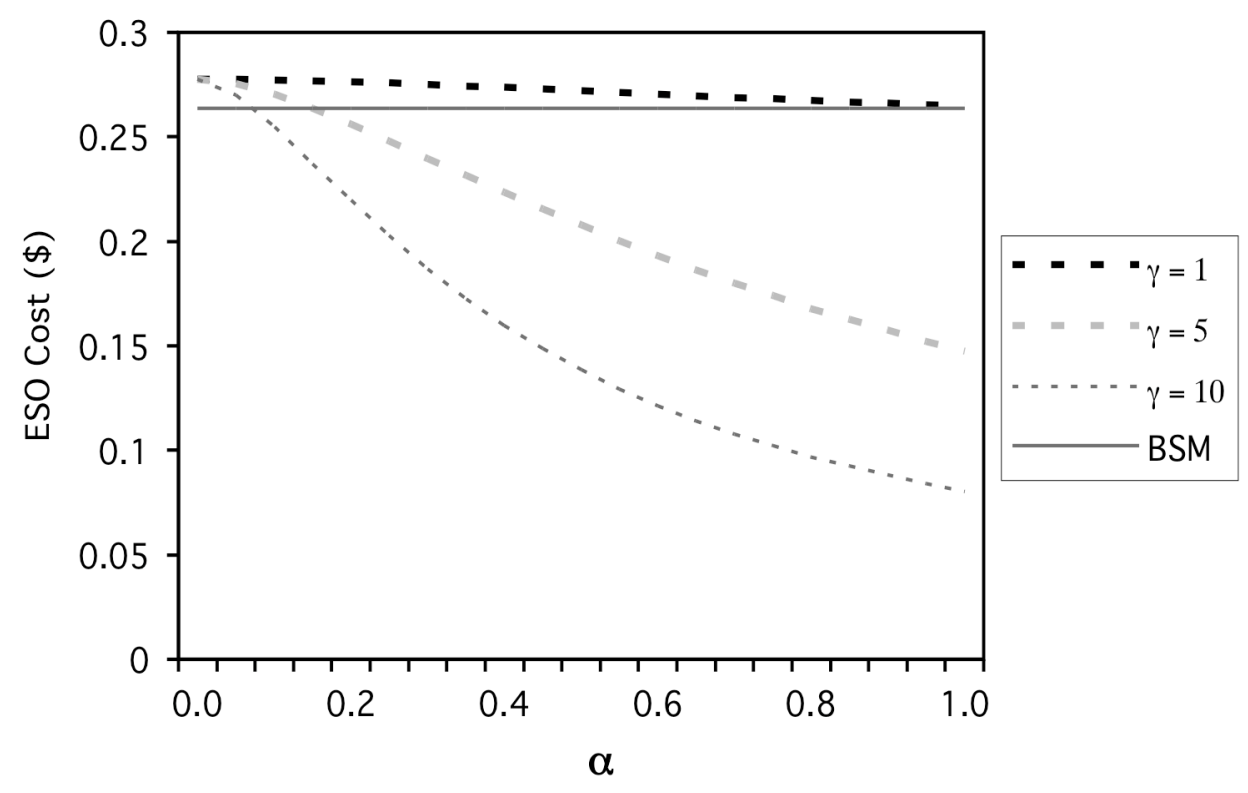


Figure 4

\section{Valuing ESO II}

This figure plots the Ingersoll (2006) cost of ESO II for various combinations of employee risk aversion $(\gamma)$ and under-diversification $(\alpha)$, and compares these with the Black-Scholes-Merton (BSM) value. Parameter values for ESO II are in Table 1.

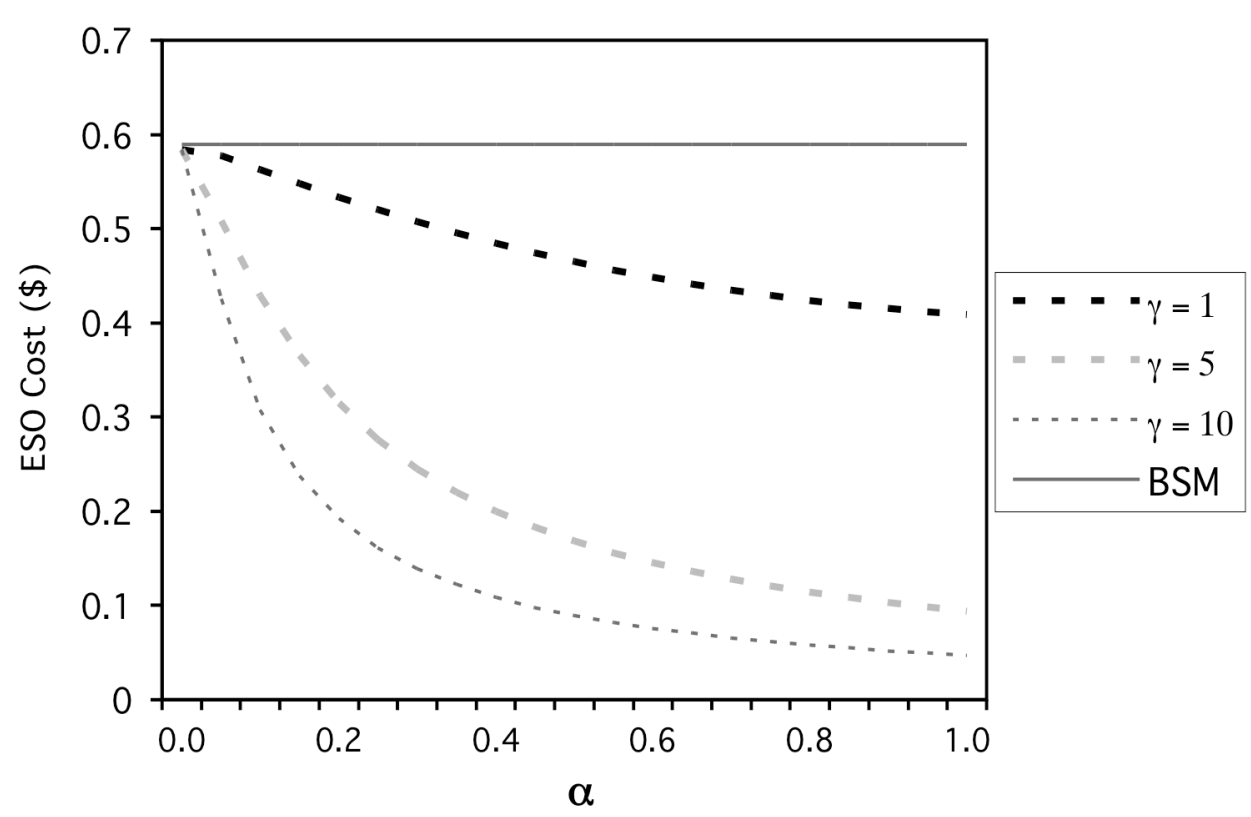


Figure 5

The Effect of setting Time to Expiration equal to Vesting Date plus One Month in the BSM Model

This figure plots the Ingersoll (2006) ESO cost for various combinations of employee risk aversion $(\gamma)$ and under-diversification $(\alpha)$, and compares these with the BlackScholes-Merton (BSM) value when the time to expiration is set equal to one month after the vesting date. Parameter values for the two ESOs are in Table 1.

Panel (a): ESO I

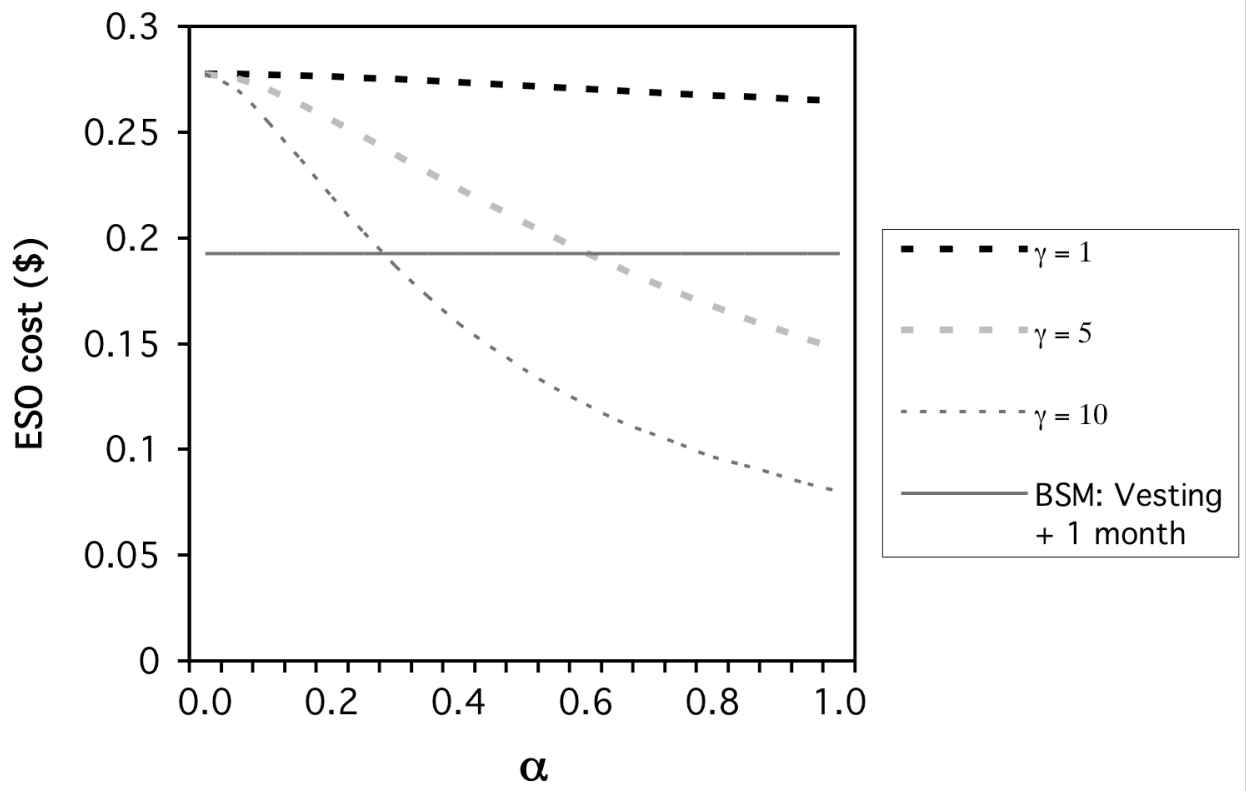

Panel (b): ESO II

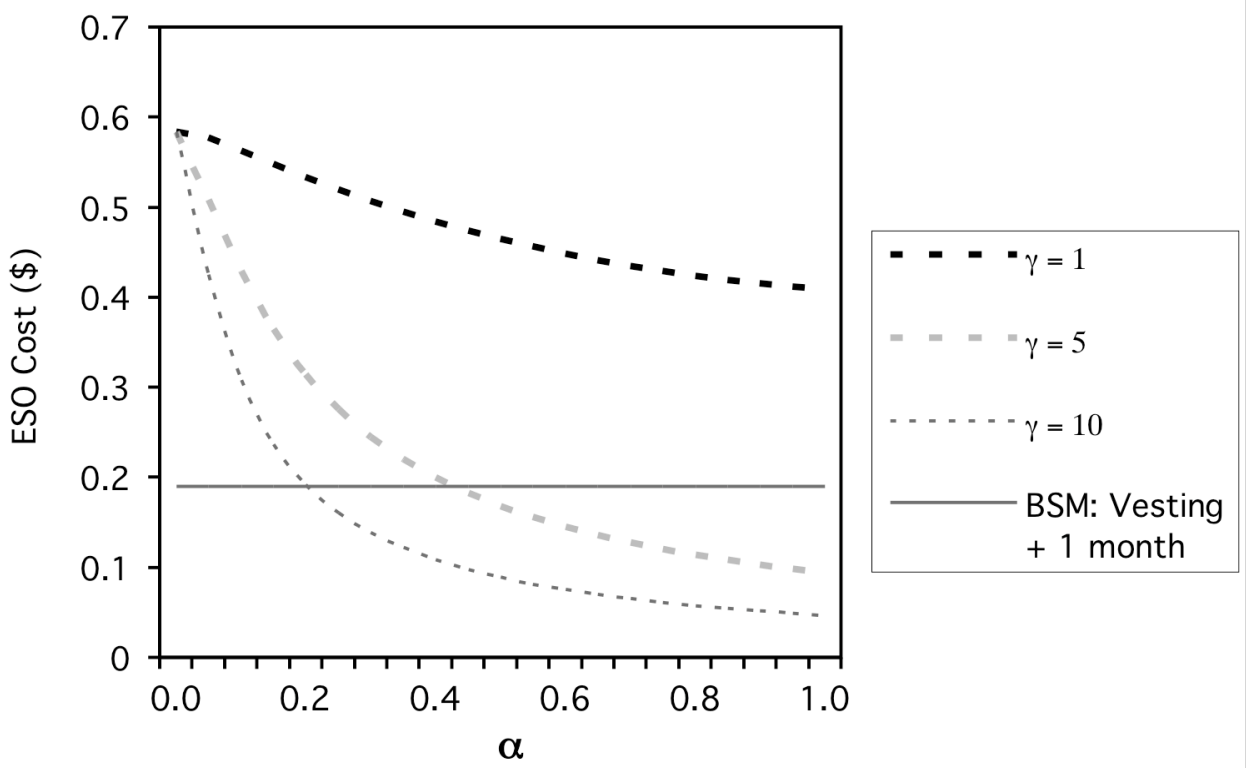


Figure 6

The Effect of Vesting on ESO Cost

For an employee with $\gamma=5$, this figure plots the Ingersoll (2006) cost of ESO II where (i) the ESO does not vest for six months and (ii) the ESO has already vested.

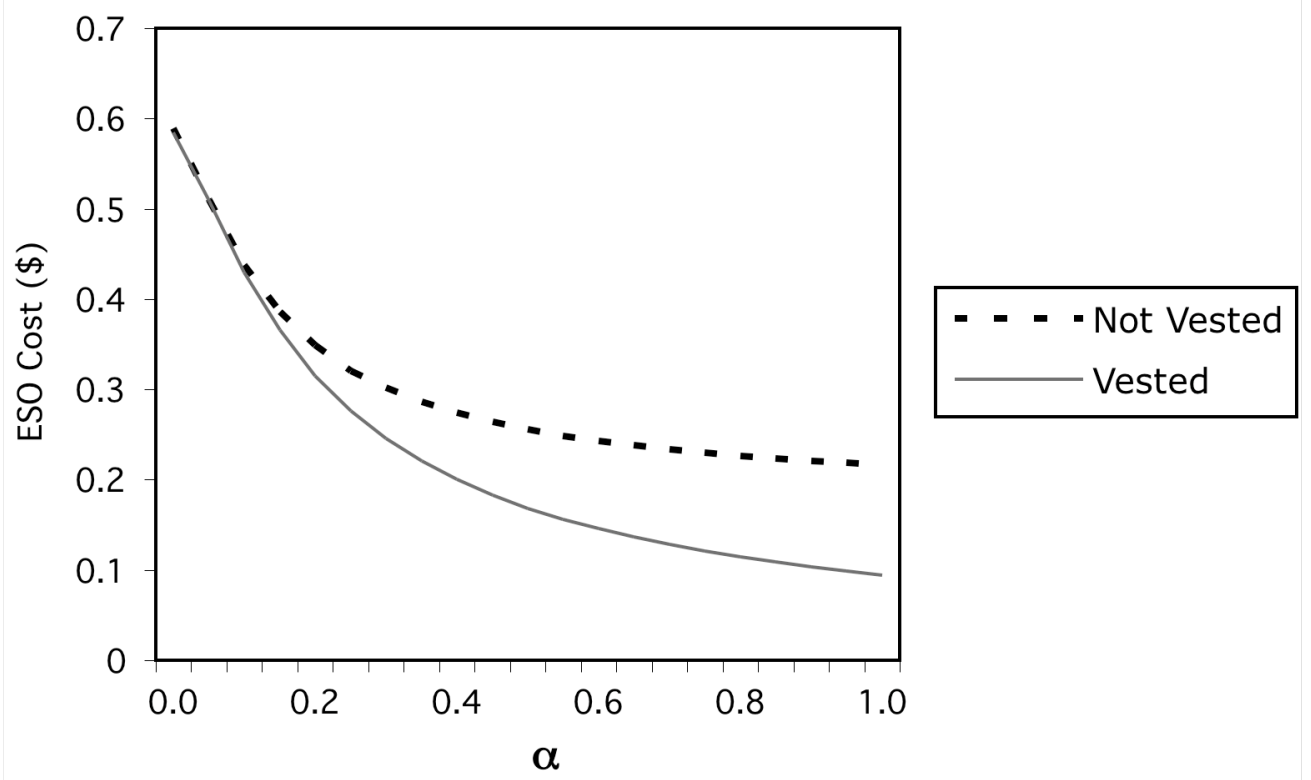

